\title{
Reliability estimation of the milling machines teeth obtained by welding deposition process
}

\author{
Daniela Maria Iovanas ${ }^{1, *}$, and Adela-Eliza Dumitrascu $^{2}$ \\ ${ }^{1}$ Transilvania University of Brasov, Department of Materials Engineering and Welding, 1 Colinei \\ Street, 500084 Brasov, Romania \\ ${ }^{2}$ Transilvania University of Brasov, Department of Manufacturing Engineering, 5 M. Viteazul Street, \\ 500174 Brasov, Romania
}

\begin{abstract}
Currently, governments and authorities worldwide allocate annually significant amounts of money in an attempt to maintain the existing road infrastructure functional and safe. In our country too there is this concern to rehabilitate a significant number of damaged road structures and to create new modern ones. The research presented in this paper focused on applying modern manufacturing technologies, loading by welding the milling teeth for stripped asphalt road structures in order to increase their reliability. It was thus estimated the reliability of classical teeth made from $41 \mathrm{Cr} 4$ and teeth manufactured through loading by welding with special filler materials in the active surfaces, which grants them self-protection systems from wear and locking in rotation and which equipped a Wirtgen 50 milling machine in operation on one of the national roads.
\end{abstract}

\section{Introduction}

One of the most important types of transport which recorded a significant development both countries wide and worldwide is road transport.

The special role played by the road in the development of road transport is represented by the diversification of the network, which allows the performance of transport between the loading and unloading points, as well as by the effects of the state of roads on vehicles.

A great importance in the accomplishment of the above is played by the earthmoving equipment, respectively, milling machines for topsoil stripping.

In the literature are presented numerous examples of milling cutters made of various materials, with different geometries, with carbide or diamond inserts, with planar or mobile active surfaces, working at variable pressures and having different wear [1-6]. The disadvantage of the advanced solutions consists in the complexity of the manufacturing processes, plus high costs and low reliability.

The research presented in this paper focused on the implementation of some modern manufacturing technologies, namely, loading by welding the milling teeth for topsoil stripping in order to increase their durability and reliability.

*Corresponding author: daniela.iovanas@yahoo.com 


\section{Milling teeth}

Worldwide, there is a large number of companies which produce asphalt milling machines in various constructive versions (Fig. 1, a, b, c) which differ not only in terms of shape and sizes of the active parts, but also in terms of the nature of the milled material, the used milling technology, the milling depth and the characteristics of the milling equipment [7].

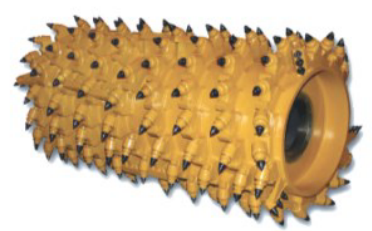

(a)

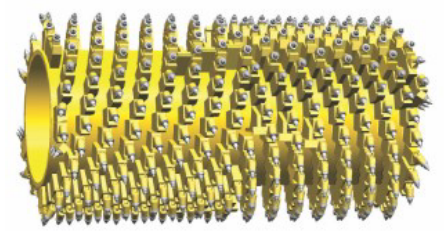

(b)

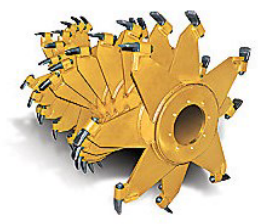

(c)

Fig. 1. Constructive versions of mills: (a) standard mill, (b) mill for micro-profiles and small depths, (c) recycling mill.

The main part of the mills is the milling drum (Fig. 2), made of a metal cylinder (1), on which the teeth are attached (2) through a special base (3).

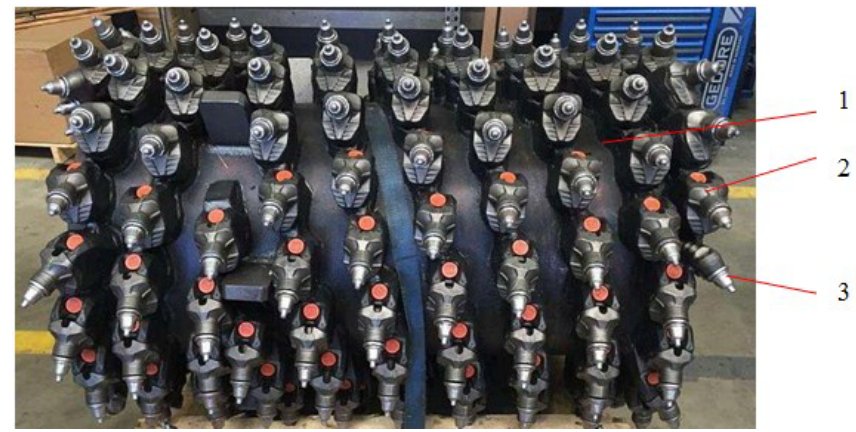

Fig. 2. Road structure milling drum: 1 - drum, 2 - milling tooth, 3 - mounting base.

The important active part of the mills used for stripping asphalt road structures is the milling tooth (Fig. 3), also named cutting tool. The main elements which make up the tooth itself are: the tooth body (1), the tooth tip (2) made of wolfram carbides and fixed in the body through abrasion and the elastic mounting element (3).

In practice, several versions are used for the manufacture of teeth, which differ not only in terms of the shape and size of the active parts, but also in terms of the shape and sizes of the wolfram carbide tip, according to the manufacturing company and the destination [7].

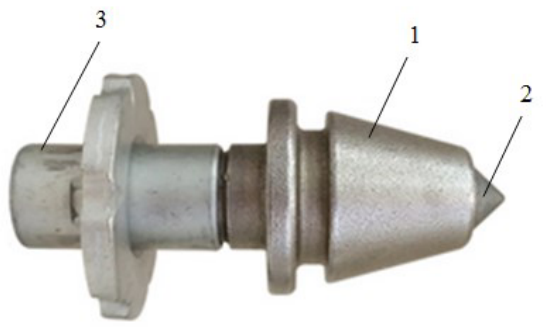

Fig. 3. Milling tooth: 1 - body, 2 - wolfram carbide point, 3 - fixing element. 
During the milling process, the tip of the sintered wolfram carbide tooth undergoes intense usage through high pressure abrasion. On the other hand, the tooth body also undergoes wear due to the rough contact with the particles of the asphalt mixture. All of these lead, eventually, to the self-locking of the milling teeth in the rotation around their own axis and, consequently, to their early disuse [7,8].

To that end, in order to increase wear resistance and to fight back these wear phenomena, research focused on obtaining, through loading by welding, intelligent wear and locking protection systems of the various types of milling teeth for the stripping of asphalt road structures, in order to improve their reliability [7-9].

Fig. 4 illustrates a milling tooth with the two active areas [8], respectively, the wolfram carbide tip (1) and the tapered part of the tooth body (4), whose wear resistance is meant to be improved by placing, through fusion welding, several layers (2) of proper width and thickness, with high resistance to wear and to locking during the rotation around its own axis.

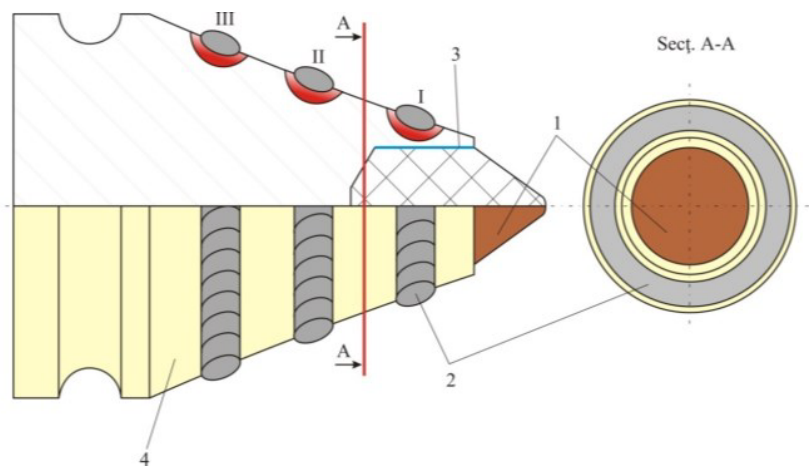

Fig. 4. Loaded milling tooth: 1 - wolfram carbide tip, 2 - circular bands obtained through loading by welding, 3 - abrasion area of the wolfram carbide tip in the frontal orifice, 4 - tapered part of the milling tooth.

The fusion welding procedures used in the research for the achievement of the loading by welding of the tapered part of the milling tooth, as well as the filler materials used in experiments are illustrated in Table 1, [10].

Table 1. Procedures and filler materials used in the experiments.

\begin{tabular}{|c|c|c|c|}
\hline No. & Welding procedure & $\begin{array}{c}\text { Welding procedure symbol } \\
\text { (EN ISO 4063) }\end{array}$ & Filler material \\
\hline 1. & WIG & 141 & $\begin{array}{c}\text { Tubular wire } \\
\text { FILEUR DUR 606 B }\end{array}$ \\
\hline 2. & WIG & 141 & $\begin{array}{c}\text { Tubular rod } \\
\text { VTCr2.5TiD }\end{array}$ \\
\hline 3. & $\begin{array}{c}\text { MIG / MAG - Cold } \\
\text { metal }\end{array}$ & $135 / 136$ & $\begin{array}{c}\text { Tubular rod } \\
\text { FILEUR DUR 606 B }\end{array}$ \\
\hline
\end{tabular}

\section{Estimating the reliability of the milling teeth manufactured through loading by welding}

The study consists in estimating the reliability of the milling teeth manufactured through various loading by welding procedures to be used in road rehabilitation structures. The data required for appreciating reliability were gathered directly from the exploitation of a 
Wirtgen 50 milling machine used for the topsoil stripping of a road in Arad County, fitted with 50 teeth which worked for an 8-hour cycle and then were entirely replaced [8]. Given the rough working conditions, the milling machine is stopped at regular intervals (approximately 2 hours), for cooling and inspection. The periodic inspection, in this case, consisted in the thorough analysis of each tooth (after flushing it with water), estimating the wear degree of each and the manner in which it was produced. Even if the degree of wear in some milling teeth was high, the teeth were kept until the end of the working cycle ( 8 hours).

Practically, we managed to fit the milling machine with the tested milling teeth, per tooth batches, as follows:

$>$ with classical teeth made of $41 \mathrm{Cr} 4$, type $\mathrm{B},-$ used in this type of mill, (version I);

$>$ with teeth obtained through loading by means of the MIG/MAG (CMT) welding procedure; filler material: tubular wire type FILEUR DUR 606B, (version II);

with teeth obtained through loading by means of the WIG welding procedure; filler material: tubular wire type FILEUR DUR606B, (version III);

$>$ with teeth obtained through loading by means of the WIG welding procedure; filler material: tubular rod VTCr2,5TiD, (version IV).

For analysing reliability, first we identified the statistical model most adequate for such an analysis [11-15]. The experimental data were validated using Anderson-Darling adequacy test in order to determine whether a sample comes from a population with a specific distribution. After applying the test, we adopted normal distribution.

The estimation of the reliability of the milling teeth for the four procedure types was made using the Minitab software. Based on the experimental data, we estimated the main reliability indices of the milling teeth (PDF-probability density function, reliability function and hazard rate) using least squares method (Fig. 5 to Fig. 8).

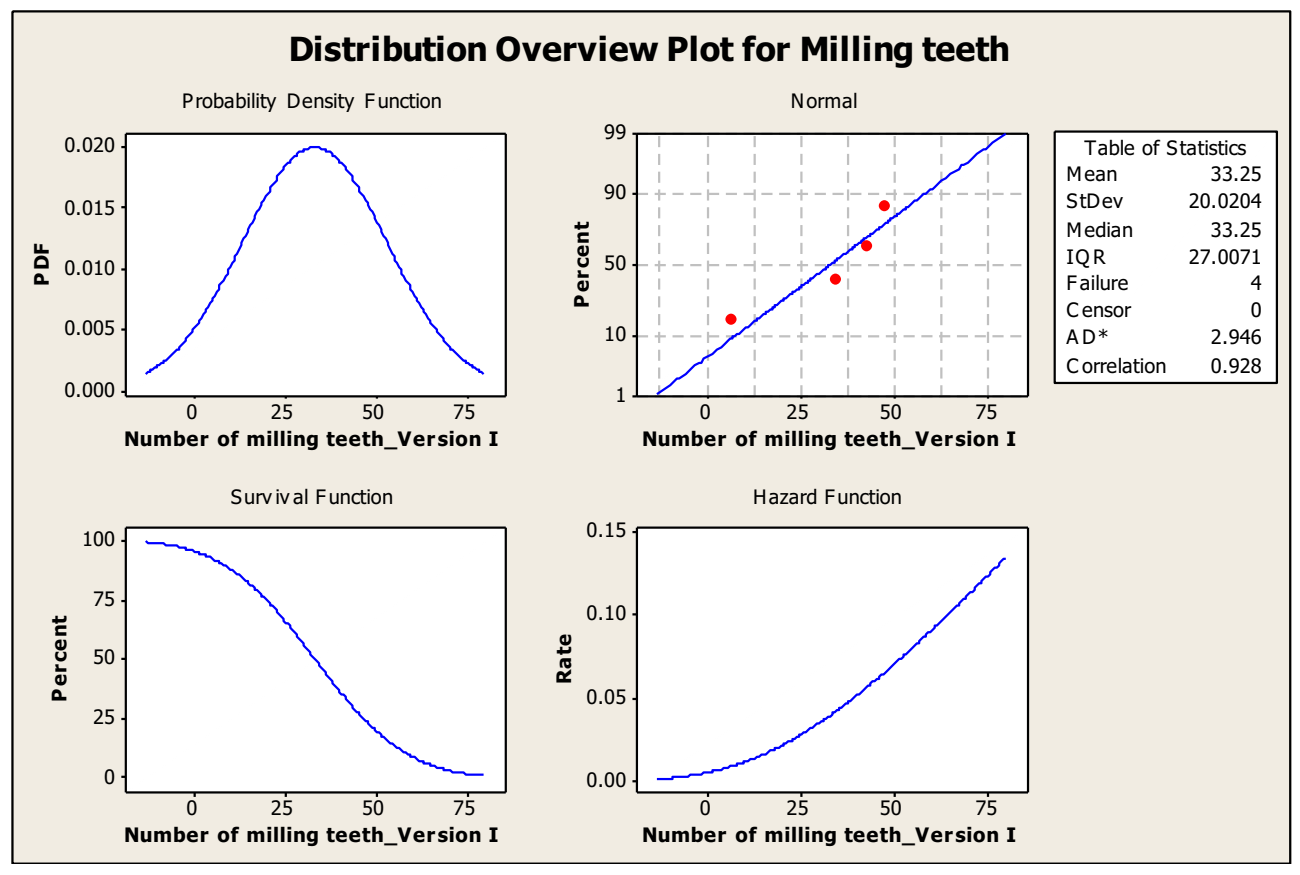

Fig. 5. Reliability indices estimation of milling teeth - version I. 


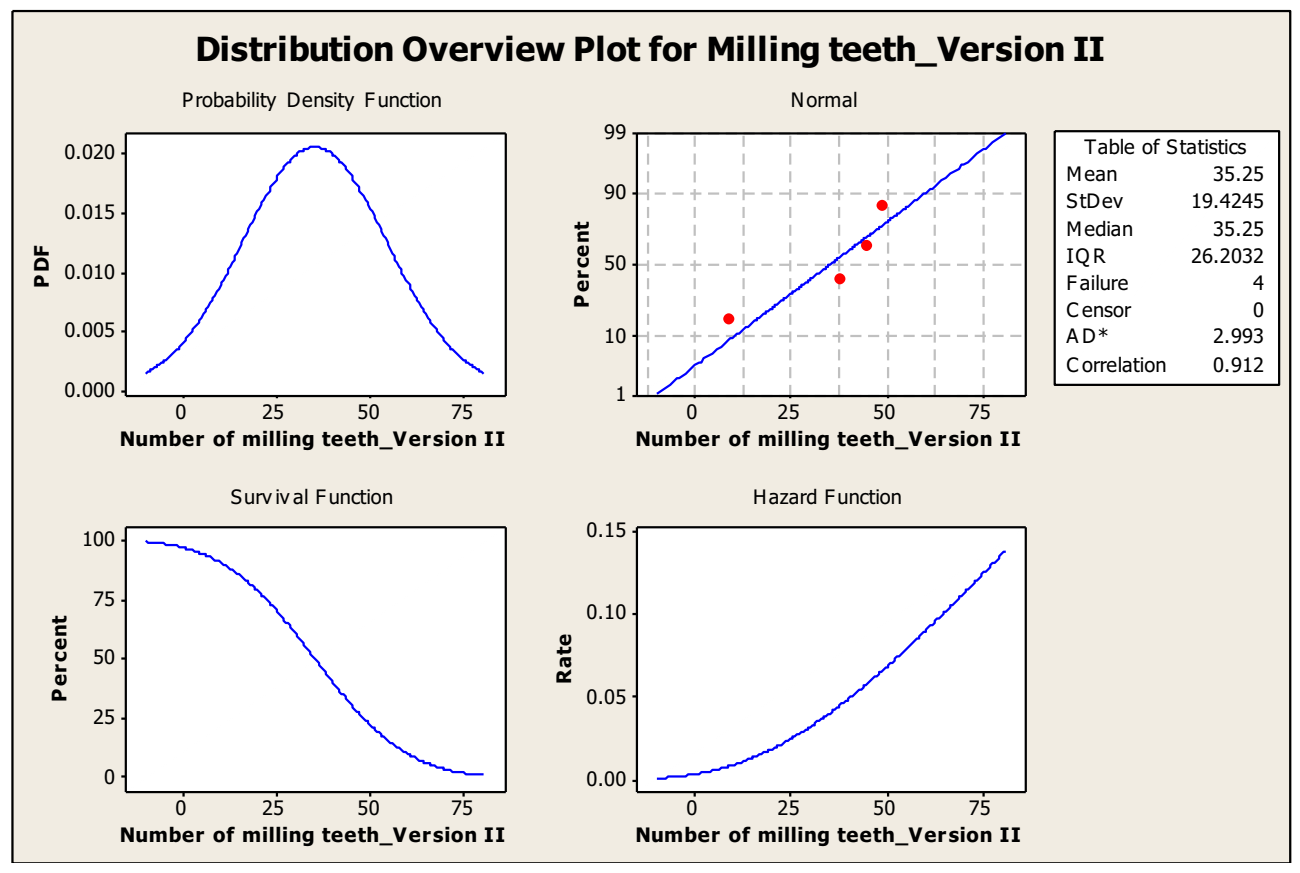

Fig. 6. Reliability indices estimation of milling teeth - version II.

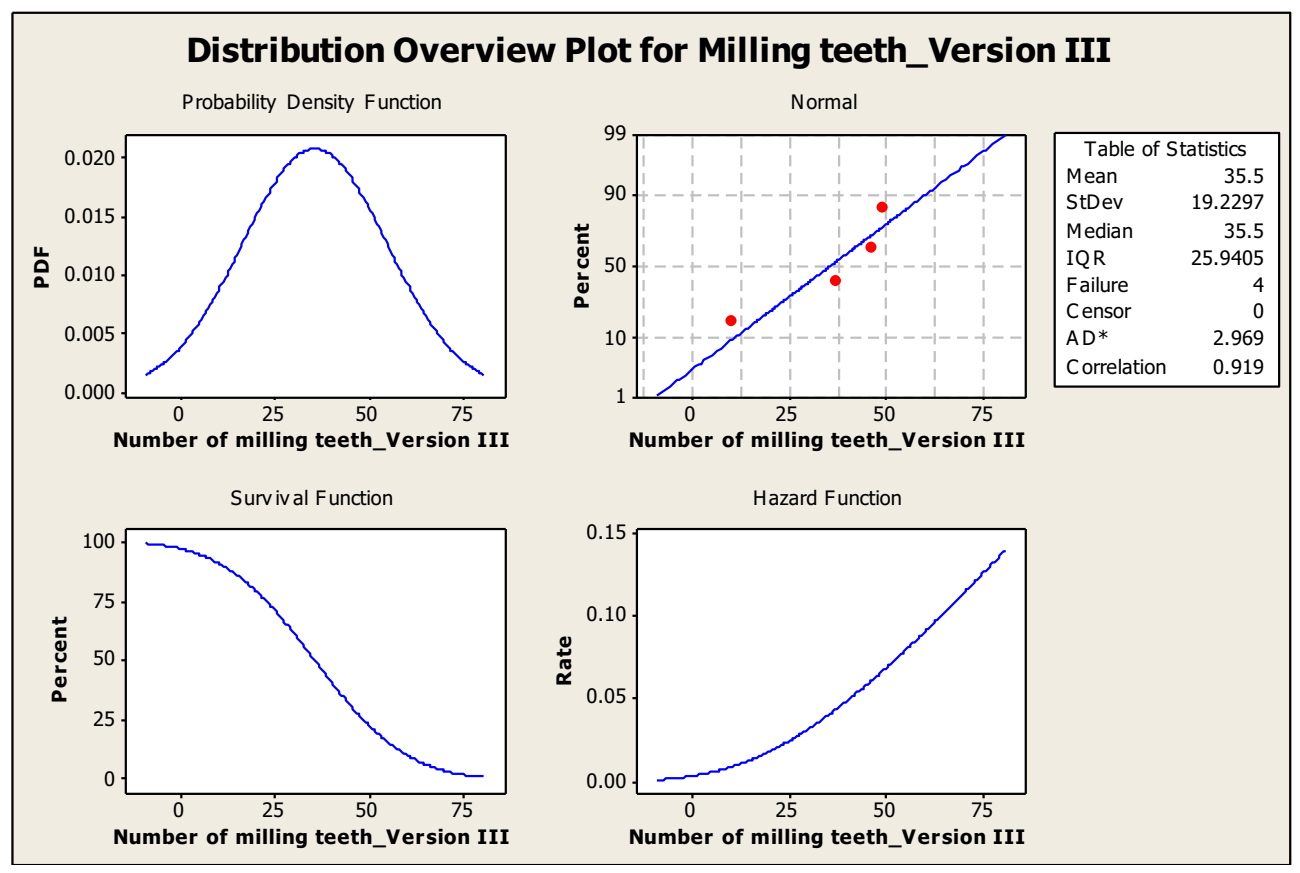

Fig. 7. Reliability indices estimation of milling teeth - version III. 


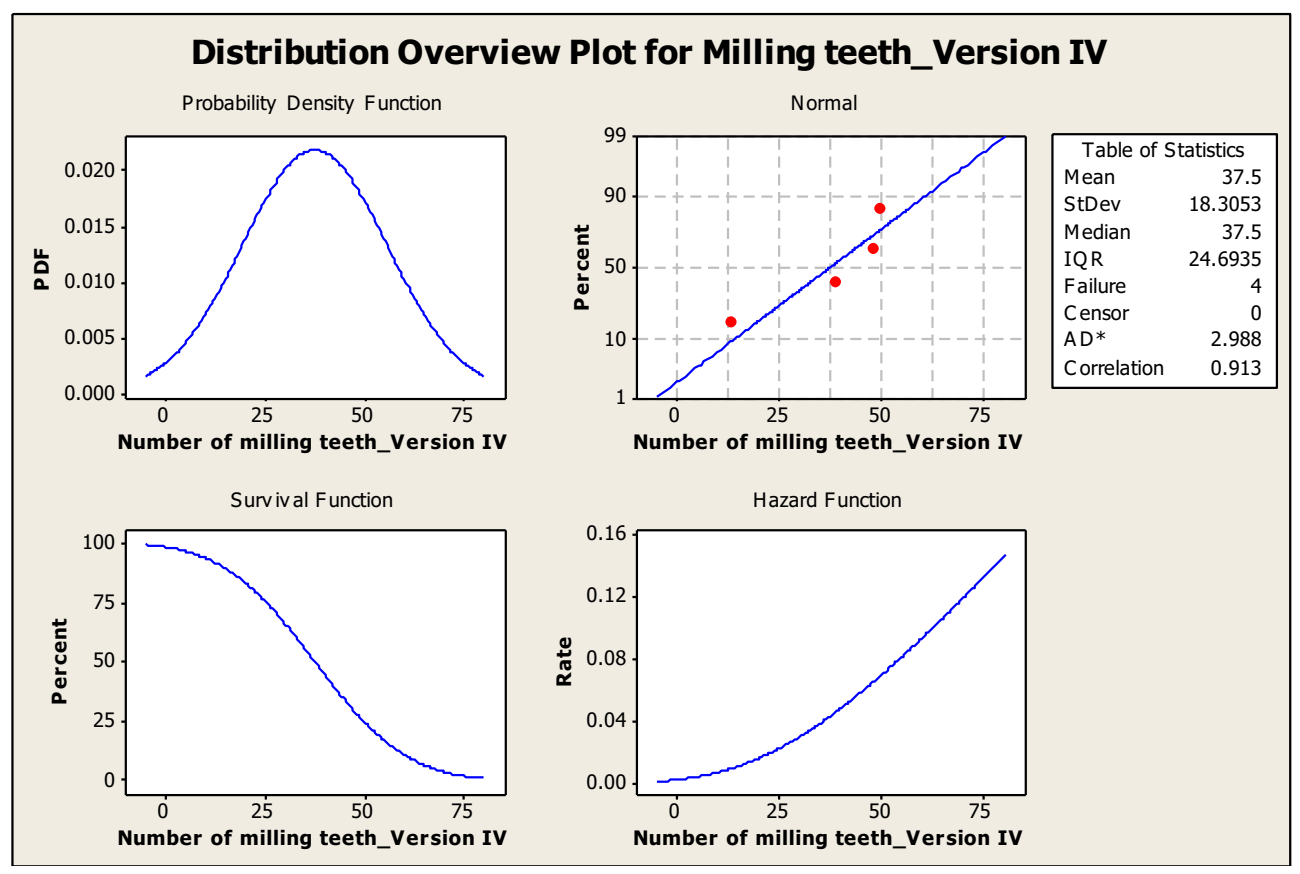

Fig. 8. Reliability indices estimation of milling teeth - version IV.

\section{Conclusions}

Based on the analyses made on the milling teeth, we found that the evolution of wear is exacerbated after 4 hours of operation, most of it being caused by self-locking during rotation, thus resulting a preferential wear (on only one side). This was seen especially in the milling teeth tested in versions I, II and III. In version IV, the wear was fairly symmetrical (sharpening effect), which means that the self-locking effect was significantly reduced.

In terms of reliability, after 6 hours of operation, we notice a significant decrease of reliability in all the analysed types. Analysing the reliability of the milling teeth obtained through the different loading by welding procedures, the milling teeth obtained by loading using the WIG welding procedure, with tubular rod type VTCr2,5TiD have a better reliability as compared to the other studied versions.

\section{References}

1. E.J. Oles, L.E. Thomas, US Patent 61619090 (2000)

2. D. R. Hall, R. B. Crockett, J. Jepson, J. Fox, M. Barnhill, US Patent 7469972 (2008)

3. D. R. Hall, J. Bailey, R. B, Crockett, US Patent 7669938 (2010)

4. S.G. Patel, M. George, R.J. McClellan, P.E. Pastusek, I.R. Rugashoborola, N.J. Lyons, US Patent 7814998 (2010)

5. D.R. Hall, R.B. Crockett, US Patent 8028774 (2011)

6. A. Binchiciu, I. Voiculescu, V. Geantă, H. Binchiciu. R. Ştefănoiu, D. Iovănaş, E. Binchiciu, R. M. Negriu, RO Patent 125760 (2011)

7. R.F. Iovănaş, Theoretical and experimental research on increasing the durability and reliability of equipments, manufactured by weld cladding, visible on earth drilling equipments, $\mathrm{PhD}$ thesis, Transilvania University of Brasov (2012) 
8. *** http://www.matfrez.ro/, accesed 10.02.2017

9. E. Binchiciu, V. Geanta, I. Voiculescu, R. Stefanoiu, R. F. Iovanas, A. Binchiciu, H. Binchiciu, RO Patent A/00375 (2012)

10. D. M. Iovanas, Welding load of the used parts to the earthmoving equipments (in Romanian: Incărcarea prin sudare a pieselor uzate la utilajele terasiere), (Lux Libris Publishing House, 2013)

11. M. Comandini, G. Olmi, A. Freddi, Transactions of Famena 31, 2 (2007)

12. J. Stodola, P. Stodola, Transactions of Famena 33, 1 (2009)

13. A.-E. Dumitraşcu, B. Lepadatescu, D.-I. Dumitraşcu, A. Nedelcu, D.V. Ciobanu, The Scientific World Journal, Article ID 296762, 2015 (2015)

14. D.C. Montgomery, G.C. Runger, Applied statistics probability engineers. 5th Edition (John Wiley \& Sons, Inc., New-York, 2011)

15. Anderson-Darling Test Engineering Statistics Handbook, (2013), available at: www.itl.nist.gov/div898/handbook/eda/section3/eda35e.htm; accesed 17.03.2017 